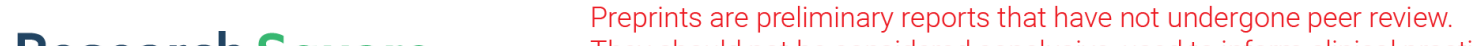 They should not be considered conclusive, used to inform clinical practice, or referenced by the media as validated information. \\ Tertiary Butylhydroquinone Ameliorates Insulin Resistance and Liver Steatosis in Type 2 Diabetes Mellitus
}

\section{Tiantian Zhu}

Xinxiang Medical University

Chaonan Zhu

Xinxiang Medical University First Affiliated Hospital

\section{Ning Huang}

Xinxiang Medical University

Tianheng Liu

Xinxiang Medical University

\section{Shuangxi Wang}

Xinxiang Medical University

\section{Guangrui Wan}

Xinxiang Medical University

\section{Ping Song}

Xinxiang Medical University

Jian Xu

Xinxiang Medical University

\section{Peng Li}

Xinxiang Medical University

Yaling Yin ( $\sim$ hnpdsyyl@163.com )

Xinxiang Medical University

\section{Research}

Keywords: Type 2 diabetes mellitus, Insulin resistance, Liver steatosis, Tertiary butylhydroquinone, AMPKa2

Posted Date: October 29th, 2020

DOI: https://doi.org/10.21203/rs.3.rs-97492/v1

License: (a) (i) This work is licensed under a Creative Commons Attribution 4.0 International License. 



\section{Tertiary butylhydroquinone ameliorates insulin resistance and liver steatosis in}

type 2 diabetes mellitus

Tian-tian Zhu ${ }^{123 \#}$, Chao-nan Zhu ${ }^{1235 \#}$, Ning Huang ${ }^{123 \#}$, Tian-heng Liu ${ }^{123}$,Shuang-xi Wang $^{123}$, Guang-rui Wan ${ }^{123^{*}}$, Ping Song ${ }^{123} *$, Jian $\mathrm{Xu}^{123^{*}}$, Peng $\mathrm{Li}^{123^{*}}$, Ya-ling Yin ${ }^{234^{*}}$

1 College of Pharmacy, Xinxiang Medical University, Xinxiang, 453003,China

2 Henan international joint laboratory of cardiovascular remodeling and drug intervention, Xinxiang, 453003, China

3 Xinxiang key laboratory of vascular remodeling intervention and molecular targeted therapy drug development, Xinxiang, 453003, China

4 School of Basic Medical Sciences, Xinxiang Medical University, Xinxiang, China

5 Department of pharmacy, Xinxiang Medical University First Affiliated Hospital, Xinxiang, 453003, China

\# Both authors contributed equally to this work

*To whom correspondence should be address

*Corresponding author:

Peng Li, College of Pharmacy, Xinxiang Medical University, 601 Jinsui Road, Xinxiang 453003, Henan, China. Tel: 0086-373-3029918; Fax: 0086-373-3029918;

E-mail: 071021@xxmu.edu.cn

Yaling Yin, School of Basic Medical Sciences, Xinxiang Medical University, 601 Jinsui Road, Xinxiang 453003, Henan, China. Tel: 0086-373-3029918; Fax: 0086-373-3029918; E-mail: hnpdsyyl@ 163.com

Guangrui Wan, PhD, College of Pharmacy, Xinxiang Medical University, No. 601 Jin-sui Road, Xinxiang 453003, Henan, China. Tel: 86-373-3029918; Fax: 86-0373-3029918; Email: wgrxxmu@163.com

Ping Song, PhD, College of Pharmacy, Xinxiang Medical University, No. 601 Jin-sui Road, Xinxiang 453003, Henan, China. Tel: 86-373-3029918; Fax: 86-0373-3029918; Email: songpingxxmu@163.com

Jian Xu, PhD, College of Pharmacy, Xinxiang Medical University, No. 601 Jin-sui Road, Xinxiang 453003, Henan, China. Tel: 86-373-3029918; Fax: 86-0373-3029918; Email: xujianxxmu@163.com 


\begin{abstract}
:
Aims: This study aimed to evaluate the effects and mechanisms of tertiary butylhydroquinone (TBHQ) on insulin resistance (IR) and diabetic liver steatosis.

Methods: Male ApoE ${ }^{-/-}$mice were received streptozocin (STZ) injection and a high-sugar-high-fat diet to form type 2 diabetes mellitus (T2DM). Then, the mice were given TBHQ for six weeks. Body weight, fasting blood-glucose (FBG), postprandial blood glucose (PBG), insulin and oral glucose tolerance test (OGTT) were detected on all the mice. Hematoxylin-eosin staining and western-blot were performed to detect the morphological structure and the target proteins expression in liver tissues. In vitro, HepG2 cells were induced by $\mathrm{HClO}$ and insulin to develop IR. Western-blot was used to evaluate the related proteins expression. Hoechst staining was conducted to measure cell apoptosis.

Results: Mice that received STZ injection and a high-sugar-high-fat diet developed T2DM. TBHQ reduced blood glucose level, improved glucose tolerance, alleviated liver steatosis in diabetic mice. Moreover, TBHQ significantly increased AMPK $\alpha 2$, GLUT4 and GSK3 $\beta$ expression, up-regulated PI3K and AKT phosphorylation level in diabetic mice liver. Notably, TBHQ down-regulated HClO and insulin-induced cell IR and inhibited cell apoptosis via AMPKa2/PI3K/AKT pathway.
\end{abstract}

Conclusion: TBHQ alleviated IR and liver steatosis in T2DM mice and the mechanism may relate to AMPK $\alpha 2 / \mathrm{PI} 3 \mathrm{~K} / \mathrm{AKT}$ pathway.

Keywords: Type 2 diabetes mellitus, Insulin resistance, Liver steatosis, Tertiary butylhydroquinone, AMPKa2 


\section{List of abbreviations}

\begin{tabular}{|c|c|}
\hline AKT & protein kinase $\mathrm{B}$ \\
\hline AMPK & AMP-activated protein kinase \\
\hline BCA & bicinchoninic acid \\
\hline DMEM & dulbeccoo's modified eagle' s medium \\
\hline ELISA & enzyme-linked immunosorbent assay \\
\hline FBG & fasting blood glucose \\
\hline FBS & fetal bovine serum \\
\hline GLUT4 & glucose transport-4 \\
\hline GSK3 $\beta$ & glycogen synthase kinase- $3 \beta$ \\
\hline $\mathrm{HClO}$ & hypochlorous acid \\
\hline $\mathrm{HE}$ & hematoxylin-eosin \\
\hline IDF & International Diabetes Federation \\
\hline IR & insulin resistance \\
\hline OGTT & oral glucose tolerance test \\
\hline PAGE & polyacrylamide gel electrophoresis \\
\hline PBG & postprandial blood glucose \\
\hline PI3K & phosphatidylinositol 3-kinase \\
\hline PVDF & polyvinylidenefluoride \\
\hline SDS & sodium dodecyl sulfate \\
\hline STZ & streptozocin \\
\hline siRNA & small interference ribose nucleic acid \\
\hline T2DM & type 2 diabetes mellitus \\
\hline TBHQ & Tertiary butylhydroquinone \\
\hline
\end{tabular}




\section{Key Messages}

Tertiary butylhydroquinone can treat type 2 diabetes mellitus.

\section{Introduction}

According to the $8^{\text {th }}$ edition of the Global Diabetes Map published by the International Diabetes Federation (IDF), there are almost 425 million people suffering from diabetes worldwide, and it is estimated that there will be nearly 700 million people with diabetes by 2045. Among them, patients with type 2 diabetes mellitus (T2DM) account for more than $90 \%^{[1]}$. T2DM is due to insulin resistance (IR $)^{[2,3]}$, characterized by a defect of the peripheral tissues, including liver, adipose tissues, and skeletal muscles, in response to insulin ${ }^{[4]}$. IR is the core mechanism of T2DM and thus has become the main target of T2DM treatment at this stage ${ }^{[5,6]}$.

Tertiary butylhydroquinone (TBHQ) is the most commonly used synthetic antioxidant ${ }^{[7]}$ and can enhance the effect of insulin in vivo ${ }^{[8,9]}$. TBHQ could also remarkably increase the phosphorylation level of protein kinase B (AKT), which could reflect insulin sensitivity ${ }^{[10]}$ in hepatocytes and nerve cells ${ }^{[11]}$. However, the underlying mechanism of TBHQ increasing AKT phosphorylation thus enhancing insulin effect is unclear.

The AMP-activated protein kinase (AMPK) is a heterotrimeric protein composed of a catalytic subunit $(\alpha)$, which have two isoforms $(1 \alpha$ and $2 \alpha)$, and two regulatory subunits $(\beta$ and $\gamma$ ). The $2 \alpha$ subunit isoform, PRKAA2, is mainly found in liver. It is reported that TBHQ has an activation effect on AMPK $\alpha 2$ factor ${ }^{[12]}$, which leads to inhibiting glucose production ${ }^{[13]}$ and regulating of insulin sensitivity ${ }^{[14-17]}$ in liver.

Based on these reports, we speculated that the protective effect of TBHQ on liver function in diabetes may be due, in part, to the ability of TBHQ to up-regulation gene expression of AMPK $\alpha 2$ factor.

\section{Materials and methods}

\subsection{Materials}

Tertiary butylhydroquinone (TBHQ), streptozocin (STZ), insulin and $\mathrm{HClO}$ were purchased from Sigma. Chemical formula of TBHQ is as follows.

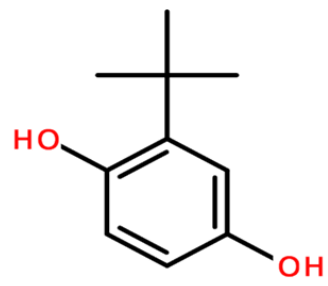


Fetal bovine serum (FBS) and dulbeccoo's modified eagle' s medium (DMEM) were obtained from Gibco BRL. Bicinchoninic acid (BCA) protein assay kit, hematoxylin-eosin (HE) staining kit and the Hoechst staining kit were purchased from Beyotime Biotechnology Co., Ltd.. p-AKT, AMPK $\alpha 2$, glycogen synthase kinase-3 $\beta$ (GSK3 $\beta$ ) and glucose transport-4 (GLUT4) were purchased from Abcam. Phosphatidylinositol 3-kinase (PI3K) and AKT were purchased from Shanghai Sangon Co., Ltd.. p-PI3K was obtained from Cell Signaling Technology. $\beta$-actin was purchased from Beyotime Biotechnology Co., Ltd.. PRKAA2 small interference ribose nucleic acid (siRNA) and riboFECT ${ }^{\mathrm{TM}} \mathrm{CP}$ transfection kit were obtained from Guangzhou RiboBio Co., Ltd..

\subsection{Protocols for animal experiments}

Male $\mathrm{ApoE}^{-/-}$mice were obtained from Model Animal Research Center GemPharmatech Co., Ltd. of Nanjing University. These animals researches were approved by the Zhengzhou University Veterinary Medicine Animal Care and Use Committee. Mice were maintained at $25^{\circ} \mathrm{C}$ under a 12-hour light/12-hour dark cycle. After one week of acclimation period, animals with a body weight of $24 \pm 0.5 \mathrm{~g}$ were randomly segregated into five groups ( $\mathrm{n}=10$ per group):

\begin{tabular}{ll}
\hline Group & Treatment \\
\hline Control & The mice were fed with a conventional diet for eleven weeks. \\
TBHQ & The mice were fed with a conventional diet for eleven weeks. During \\
& the last six weeks ${ }^{[18, ~ 19]}$, the mice were accepted intragastric \\
& administration of $60 \mathrm{mg} / \mathrm{kg}$ TBHQ. \\
T2DM & The mice were fed with a high-sucrose-high-fat diet for two weeks, \\
& then the mice were fasted for 10-h and injected STZ (50 mg/kg) \\
& which was dissolved in sodium citrate saline buffer (pH=4.5) and \\
& injected immediately within a few minutes to avoid degradation \\
& through the tail vein ${ }^{[20]}$ Last, the mice were fed a \\
& high-sucrose-high-fat diet for another two weeks to develop diabetes. \\
& The diabetic mice were fed with a high-sucrose-high-fat diet for the \\
& last six weeks.
\end{tabular}


+TBHQ The diabetic mice were fed with a high-sucrose-high-fat diet and accepted intragastric administration of $60 \mathrm{mg} / \mathrm{kg}$ TBHQ for the last six weeks.

+rosiglitazone The diabetic mice were fed with a high-sucrose-high-fat diet and accepted intragastric administration of $7 \mathrm{mg} / \mathrm{kg}$ rosiglitazone for the last six weeks ${ }^{[21,22]}$.

The high-sucrose-high-fat diet (sucrose: lard: sodium cholate: cholesterol: conventional feed=20: 10: 7: 3: 60) was given to all the mice except for the control group and the control + TBHQ group during the entire treatment period ${ }^{[23]}$. The mice were fed a high-sucrose-high-fat diet and received administrations of TBHQ or rosiglitazone after $\beta$-cell damage (Figure. 1A).

\subsection{Biochemical study}

The body weight and blood glucose of all mice were measured each week during the experimental period. All animals were anesthetized with sodium pentobarbital (30 $\mathrm{mg} / \mathrm{kg}$, i.p.) and then sacrificed by cervical dislocation at the end of the eleven weeks. The blood was collected from the mice eye socket vein and centrifuged at $4000 \mathrm{rpm}$ for $15 \mathrm{~min}$ at $4{ }^{\circ} \mathrm{C}$ to separate serum. Serum level of fasting insulin was determined by their commercially available enzyme-linked immunosorbent assay (ELISA) kits (Beyotime, Shanghai, China). The freshly isolated liver tissues were collected to analyze genes expression. The liver tissues were fixed in $4 \%$ paraformaldehyde for HE staining.

\subsection{Detection of FBG, PBG and oral Glucose Tolerance Test (OGTT)}

For FBG, blood was collected after $12 \mathrm{~h}$ of food deprivation from the tail vein of mice. For PBG, blood was collected after the mice ate 2 hours. Blood glucose was measured with an automatic blood glucose meter (Glutest Pro, Sanwa Chemical, Japan).

At the end of the experiment, OGTT was performed. For OGTT, rats were orally loaded with glucose $(1.0 \mathrm{~g} / \mathrm{kg})$ after $12 \mathrm{~h}$ of fasting. Blood glucose levels were measured as described above at the indicated time after glucose administration. The operation procedure could see literatures of Zhang WX et.al and Bin-Jumh MN et.al ${ }^{[23 \text {, }}$ 24].

\subsection{HE staining}

The freshly isolated Liver tissues were immersed in $4 \%$ aqueous buffered paraformaldehyde at the room temperature for overnight fixation and then dehydrated, 
embedded in paraffin and sliced into $4 \mu \mathrm{m}$ sections. The paraffin-embedded tissue sections were routinely stained with HE staining to conduct histologic analysis ${ }^{[25]}$.

2.6. Western blot analysis

Total protein was isolated from the Liver tissues and cultured HepG2 cells with RIPA buffer containing 1\% PMSF (Beyotime) for 30-60 min on ice. The lysates were centrifuged at $12,000 \mathrm{rpm}$ for $15 \mathrm{~min}$ at $4{ }^{\circ} \mathrm{C}$ and the protein concentrations were determined by BCA Protein Assay Kit (Beyotime, China). A fixed amount of protein (20-60 $\mu \mathrm{g})$ was separated from each sample by using 10\% sodium dodecyl sulfate polyacrylamide gel electrophoresis (SDS/PAGE). These proteins were transferred onto polyvinylidenefluoride (PVDF) membranes (Millipore, USA). Then the membranes were blocked with 5\% non-fat milk or BSA at room temperature for $1 \mathrm{~h}$, and incubated with primary antibodies at $4{ }^{\circ} \mathrm{C}$ over night, finally the membrane was washed thoroughly and incubated with a peroxidase-conjugated mouse anti-mouse or anti-rabbit antibody (1:5000; ABclonal) at room temperature for $1 \mathrm{~h}$. The chemiluminescence signals were detected using ECL (millipore). Densitometric analysis was conducted using Image J 1.43 software (National Institutes of Health, New York City, NY, USA). The specific operation steps could see articles of Zhang W et.al and Liu H et.al ${ }^{[26,27]}$. Primary antibodies against GLUT4 (1:1000, ab654, Abcam, USA), GSK3 $\beta$ (1:1000, ab32391, Abcam, USA), p-AKT (1:1000, ab38449, Abcam, USA), p-PI3K (1:1000, 17366, CST, USA), AKT (1:500, D199241, Sangon, Shanghai, China), PI3K (1:500, D162051, Sangon, Shanghai, China), AMPK $\alpha 2$ (1:1000, ab97275, Abcam, USA) and $\beta$-actin (1:1000, AF0003, Beyotime, Shanghai, China) were used.

\subsection{Cell culture and treatment}

HepG2 cells were cultured in high-glucose Dulbecco's modified Eagle's medium (DMEM) containing $10 \%$ fetal bovine serum in a $5 \% \mathrm{CO}_{2}$ atmosphere at $37{ }^{\circ} \mathrm{C}$. To formation the insulin resistant model in $\mathrm{HepG} 2$ cells, cells were exposed to $\mathrm{HClO}$ (200 $\mathrm{mM}$ ) for $40 \mathrm{~min}$ and then insulin for $25 \mathrm{~min}$. PRKAA2 siRNA (5'GTTTAGATGTTGTTGGAAAdTdT-3') and Negative control siRNA (5'-GACUACUG-GUCGUUGAACUdTdT-3') which were purchased from Ribobio (Ribobio Co. LTD, Guangzhou, China) was transfected by using ribo $\mathrm{FECT}^{\mathrm{TM}} \mathrm{CP}$ transfection kit (Ribobio Co. LTD, Guangzhou, China). Two series of experiments were designed. The first series of experiments investigated the role of hypoxia on PASMCs and the involvement of AMPKa2. The cells were divided into 8 groups as 
follows: 1) Control group, 2) TBHQ group, 3) $\mathrm{HClO}$ group, 4) Insulin group, 5) $\mathrm{HClO}+\mathrm{TBHQ}$ group, 6) $\mathrm{HClO}+$ insulin group, 7) $\mathrm{TBHQ}+$ insulin group, and 8) $\mathrm{HClO}+\mathrm{TBHQ}+\mathrm{insulin}$ group. The expression of GLUT4, GSK3 $\beta$, p-AKT, p-PI3K, AKT, PI3K, AMPK $\alpha 2, \beta$-actin and cell apoptosis were analyzed. The second series of experiments were designed to explore the role of AMPK $\alpha 2$ in diabetic liver steatosis and the involvement of the AMPK $\alpha 2 / \mathrm{PI} 3 \mathrm{~K} / \mathrm{AKT}$ pathway. The cells were divided into 12 groups as follows: 1) Control group, 2) PRKAA2 siRNA group, 3) TBHQ group, 4) TBHQ+ PRKAA2 siRNA group, 5) TBHQ+Insulin group, 6) TBHQ+ PRKAA2 siRNA+insulin group, 7) $\mathrm{HClO}$ group, 8) PRKAA2 siRNA+HClO group, 9) $\mathrm{HClO}+$ insulin group, 10) PRKAA2 siRNA+HClO+insulin group, 11) $\mathrm{HClO}+\mathrm{TBHQ}+$ insulin group, 12) PRKAA2 siRNA+HClO+TBHQ+insulin group. The expression of GLUT4, GSK3 $\beta$, p-AKT, p-PI3K, AKT, PI3K, AMPK $\alpha 2$ and $\beta$-actin were analyzed.

\subsection{Hoechst staining}

The cells (approximately 3000 cells/well) were seeded into 96-well plates with DMEM containing $10 \%$ FBS for $24 \mathrm{~h}$ before the $\mathrm{HClO}$ and insulin treatment. Then, the cells were treated with TBHQ for $30 \mathrm{~min}$. Hoechst staining kit (Beyotime, Shanghai, China) was used to detect the cell apoptosis according to the manufacturer's instructions.

\subsection{Quantitative RT-PCR analysis}

Quantitative RT-PCR analysis was conducted using the SYBR Premix Ex Taq (TaKaRa). Briefly, total RNA was extracted from HepG2 cells using a RNAiso plus kit (TaKaRa) according to the supplier's instructions. Quantitative RT-PCR was conducted to assess AMPK $\alpha 2$ expression using an ABI step one plus sequence Detection System (Applied Biosystems). GAPDH was used for normalization, and the relative expression levels for each target gene were calculated using the $2^{-\Delta \Delta \mathrm{Ct}}$ approach as previously reported ${ }^{[17]}$. The primers used to amplify each target gene were as follows: human PRKAA2: forward: 5'- GGAGAACATCAATTAACAGGCC -3', reverse: 5'- CCAACAACATCTAAACTGCGAA -3'; human GAPDH forward: 5'CAAATTCCATGGCACCGTCA-3', reverse:

$5^{\prime}-$ GGTCATGAGTCCTTCCACGA-3'was used as an internal control.

\subsection{Statistical analysis}

Statistical analysis was performed using SPSS software. All quantitative results data were expressed as mean $\pm \mathrm{SD}$. All results were performed by one-way ANOVA 
with Newman-Student-Keuls test for multiple comparisons, and both sides $P<0.05$ were considered significant.

\section{Results}

3.1. TBHQ obviously alleviated the abnormal of glucose metabolism in diabetic mice

A high-sucrose-high-fat diet treatment and STZ injection induced type 2 diabetes mellitus (T2DM). Specifically, the mice developed T2DM with significant increases in FBG and PBG concentrations in serum (Figure 1C and 1D), a rise in oral glucose tolerance test (OGTT) levels (Figure 1E), and an decrease in body weight (Figure 1B). However, after six weeks of rosiglitazone or TBHQ treatment, the FBG, PBG, OGTT levels were significantly decreased and the body weight was obviously increased. Moreover, TBHQ produced an equivalent or more evident effect on hypoglycemic activity in diabetic mice compared with rosiglitazone treatment. Taken together, these data indicate that the persistent application of TBHQ relieves glucose metabolic abnormalities and the body weight increase in T2DM mice.

3.2. TBHQ effectively alleviated liver steatosis of diabetic mice and increased cell survival in HepG2 cells

HE staining (Figure 2A) revealed that in normal mice, no abnormality of the hepatocyte architecture and morphology were observed. The hepatocytes were arranged in cords and radiated around the central vein. In the liver of T2DM mice, severe hepatocyte necrosis and macrovesicular steatosis were appeared. However, after rosiglitazone or TBHQ treatment, the degeneration of the hepatocyte was markedly alleviated, the macrovesicular steatosis and cell death were partially recovered. These results demonstrate that the persistent application of TBHQ exhibited a beneficial effect on diabetes-mediated pathological changes of the mice liver.

Hoechst staining was used to explore the effect of TBHQ on HepG2 cells apoptosis. As shown in Figure $2 \mathrm{~B}, \mathrm{HClO}$ and insulin treatment promotes cells apoptosis. The number of cells with apoptotic morphology appearing condensed or fragmented nuclei was counted. However, after TBHQ treatment the number of apoptosis HepG2 cells markly downregulated. TBHQ displayed varying degrees of apoptosis $(64.65 \%$ for $\mathrm{HClO}$ group, $71.56 \%$ for $\mathrm{HClO}+$ insulin group, $23.05 \%$ for $\mathrm{HClO}+\mathrm{TBHQ}+$ insulin group, $20.08 \%$ for $\mathrm{HClO}+\mathrm{TBHQ}$ group). These results indicated that TBHQ subsequently increase the survival ability of HepG2 cells. 
3.3. Effects of TBHQ treatment on PI3K/AKT pathway in diabetic mice and insulin resistance (IR) HepG2 cells

The related proteins levels of the glucose metabolism such as GLUT4, GSK3 $\beta$, p-PI3K and p-AKT are index of diabetes and IR. We next evaluated the related proteins in hepatic cells to confirm the regulatory effect of TBHQ. We found that TBHQ increased the protein expression of the glucose transport marker GLUT4 (Figure. 3A, 3B) and the glycogen synthase marker GSK3 $\beta$ (Figure. 3C, 3D) when compared to the T2DM group and insulin resistance HepG2 cells. Moreover, the phosphorylation level of PI3K and AKT relatively elevated in diabetic mice and insulin resistance HepG2 cells treatment with rosiglitazone or TBHQ. Previous studies have showed that the phosphorylation level of AKT is upregulated by the PI3K phosphorylation ${ }^{[28-30]}$. Therefore, the AKT phosphorylation level in liver tissues and HepG2 cells were inspected to discuss whether TBHQ increased p-AKT activity by activating the PI3K pathway and then regulating gluconeogenesis. In a word, the data suggest that TBHQ may inhibit glucose uptake and increase glycogen synthesis via the PI3K/AKT pathway.

3.4. TBHQ might activate AMPK $\alpha 2$ factor in diabetic mice and HepG2 cells with IR

As a crucial cellular energy regulator, AMPKa2 plays a considerable role in glucose utilization ${ }^{[14]}$. Thus we detected AMPK $\alpha 2$ in our animal and cell experiments and found that the expression of AMPK $\alpha 2$ has significantly decreased in both diabetic mice liver and IR cells (Figure. 4A-B). However, after the treatment of TBHQ, AMPK $\alpha 2$ was significantly increased. Thus, TBHQ could correct the abnormal of glucose metabolism and increase the expression of AMPK $\alpha 2$.

3.5. TBHQ activated AMPK $\alpha 2$ factor to increase insulin sensitivity in $\mathrm{HClO}$ and insulin-treated HepG2 cells

In order to illuminate whether TBHQ could improve the glucose metabolism directly through AMPKa2, we knocked down AMPKa2 gene with PRKAA2 siRNA in HepG2 cells and the expression levels of p-AKT, p-PI3K, GLUT4 and GSK3 $\beta$ were detected, respectively. In our results, we found that in $\mathrm{HClO}$ and insulin-treated HepG2 cells the expression of p-AKT, p-PI3K, GLUT4 and GSK3 $\beta$ were significantly decreased. After the treatment of TBHQ, the expression of these genes increased, whereas, blocking of AMPK $\alpha 2$ markedly retarded TBHQ-induced upregulation of p-AKT, p-PI3K, GLUT4 and GSK3 $\beta$ (Figure. 5A-D). Taken together, 
these results suggest that TBHQ could improve the expression of GLUT4, GSK3 $\beta$, p-PI3K and p-AKT in IR HepG2 cells via AMPK $\alpha 2$ activition.

\section{Discussion}

Insulin resistance (IR) ${ }^{[2,3]}$ could lead to type 2 diabetes mellitus (T2DM), which is characterized by a defect of the liver in response to insulin ${ }^{[4]}$. TBHQ, as a food antioxidant, can increase the effect of insulin, thus reducing $\operatorname{IR}^{[7-9]}$. However, whether TBHQ can alleviate IR thus controlling liver steatosis in T2DM and the mechanisms behind the effects have not been clearly defined. Our data presented here was the first to show the effectiveness of TBHQ on improving liver steatosis in T2DM, and the mechanism of the anti-IR effect of TBHQ related to AMPK $\alpha 2 / \mathrm{PI} 3 \mathrm{~K} / \mathrm{AKT}$ pathway. The data suggested that the persistent application of TBHQ could effectively reduce the levels of blood glucose, increase the body weight, alleviate liver steatosis and activate AMPK $\alpha 2$. Also a parallel experiment in cells was conducted. In vitro studies suggested that TBHQ could increase the survival of $\mathrm{HClO}$ and insulin induced IR HepG2 cells and the mechanism related to AMPK $\alpha 2 / \mathrm{PI} 3 \mathrm{~K} / \mathrm{AKT}$ pathway. In brief, TBHQ may potentially be used as a medicinal compound for the treatment of T2DM via activating AMPK $\alpha 2 / \mathrm{PI} 3 \mathrm{~K} / \mathrm{AKT}$ pathway.

TBHQ, which has antioxidant and anti-inflammatory effects, can protect pancreatic islet cells from damage and increase the insulin sensitivity in vivo to improve T2DM. Liver tissue, as a main detoxifying organ, often damaged by metabolic overload, lipid accumulation and viruses factors. Moreover, liver tissue will occur metabolic disturbance in T2DM. TBHQ can inhibit liver cell apoptosis, which will protect the liver from acute and chronic toxin-mediated injury ${ }^{[12,31,32]}$. According to these evidences, we hypothesized that TBHQ can alleviate liver injury in T2DM, and our subsequently experiment support this point (Figure. 2).

AMPK $\alpha 2$ is a key component in the regulation of insulin sensitivity ${ }^{[33,34]}$, and the lack of AMPK $\alpha 2$ can inhibit the resistibility of insulin in glucose uptake, which leading to abnormal glucose tolerance in vivo ${ }^{[35-37]}$. TBHQ can activate AMPK $\alpha 2$ and promote the autophagy of hepatocytes, thus exerting the effect of anti-fatty acid ${ }^{[17]}$. In our experiments, we detected the expression of AMPK $\alpha 2$ both in vivo and in vitro studies. Consistently, we found that AMPK $\alpha 2$ expression was decreased in both diabetic mice liver and insulin resistance cells. However, after TBHQ treatment, the expression of AMPKa2 was significantly increased. Previous reports have suggested that insulin can tremendous decrease blood glucose by improving phosphorylates 
AKT and PI3K ${ }^{[28,29,35]}$, which is association with GSK3 $\beta$ and GLUT4 $4^{[36-37]}$. AMPK $\alpha 2$ can induce AKT activation by phosphorylating two major residues: Ser473 and Thr308 ${ }^{[38,39]}$. Thus we speculated that TBHQ alleviates IR and liver steatosis via activating AMPK $\alpha 2 / \mathrm{PI} 3 \mathrm{~K} / \mathrm{AKT}$ pathway. In order to further explore the underlying mechanism, we used AMPKa2 siRNA in HepG2 cells and found that the TBHQ could enhance the phosphorylation levels of AKT and PI3K, thus significantly improving the role of GLUT4 and GSK3 $\beta$ in the liver of diabetic mice and IR HepG2 cells. After AMPKa2 knockdown, PI3K/AKT pathway was significantly influenced. Our results suggested that TBHQ alleviated PI3K/AKT pathway directly via AMPK $\alpha 2$ activation in insulin resistance cells.

Clinical analysis has suggested that rosiglitazone should be used with caution in patients with cardiac insufficiency, severe cardiovascular disease and hypertension ${ }^{[40]}$. It also may increase the occurrence of cardiovascular complications in the treatment of T2DM. Therefore, developing high-efficiency and safe drugs that can prevent diabetes is very necessary. TBHQ is mainly used as food additive. TBHQ is safety and low toxicity, and its chemical structure is modified to enhance the antioxidant effect. More importantly, in our study we found that TBHQ can improve IR and liver steatosis except for the effect of antioxidant. Thus TBHQ is expected to be the ideal medicine for treating T2DM.

As we all know, diabetes can cause damage of the liver, skeletal muscle and fat. The shortcoming of this study is that we have only explored the effect of TBHQ on relieving liver injury, we have not probed the role of TBHQ in inhibiting the injury of skeletal muscle and fat. In the next study, we will use C2C12 and 3T3-L1 cells to research the effect of TBHQ in these diseased organs. As different tissues have different sensitivities to TBHQ, we will use multiple doses of TBHQ to explore the optimal dose of TBHQ in diabetes. Only in this way can we make TBHQ be an ideal medicine and be used as soon as possible for treating T2DM patients.

In summary, this study demonstrates that TBHQ alleviates T2DM via AMPK $\alpha 2$ activation, and then AMPKa2 mediates IR via AKT/PI3K signaling pathway (Figure. 6). Therefore, TBHQ can be a potential medicine and AMPK $\alpha 2$ is a pharmacological target for the therapy of T2DM. 


\section{Conclusion}

This study demonstrated that TBHQ can ameliorate insulin resistance and liver steatosis via AMPK $\alpha 2 / \mathrm{AKT} / \mathrm{PI} 3 \mathrm{~K}$ signaling pathway in diabetic rats. Our results provide evidence for the clinical use of TBHQ to treat T2DM. The mechanisms underlying the anti-diabetic effects of TBHQ need further elucidation.

\section{Authors' contributions}

YYL, LP and SP conceived and designed the experiments. ZTT, ZCN and LTH performed the experiments. HN and WSX analyzed the data. Wrote the paper: XJ and WGR. All authors read and approved the final manuscript.

\section{Acknowledgements}

Not applicable.

\section{Competing interests}

The authors have no conflicts of interest to declare.

\section{Availability of data and materials}

The data and materials generated or analyzed during this study are available from the corresponding author on reasonable request.

\section{Consent for publish}

The manuscript is approved by all authors for publication.

\section{Ethics approval and consent to participate}

The experimental protocol was established according to the ethical guidelines and was approved by the Experimental Animal Ethics Committee of Xinxiang medical University

\section{Funding}

This work was supported by National Natural Science Foundation of China (81874312, U1804197, 81673423, 1704168, 81800051, 182300410332), and Research Foundation of Henan Province (194200510005, 18HASTIT047, 2018GGJS102, 2017GGJS108), and Research Foundation of Xinxiang Medical University (XYBSKYZZ201626, XYBSKYZZ505319, XYBSKYZZ201812). 


\section{References}

[1] Bommer, C., Sagalova, V., Heesemann, E., et. al. (2018). Global economic burden of diabetes in adults: projections from 2015 to 2030. Diabetes Care, 41, 963-970. http://dx.doi.org/10.2337/dc17-1962

[2] Chaudhury, A., Duvoor, C., Reddy Dendi, V. S., et al. (2017). Clinical Review of Antidiabetic Drugs: Implications for Type 2 Diabetes Mellitus Management. Frontiers in Endocrinology, 8, 6. http://dx.doi.org/10.3389/fendo.2017.00006

[3] American Diabetes Association. (2019). Diabetes Care in the Hospital: Standards of Medical Care in Diabetes-2019. Diabetes Care, 42 (Suppl 1), S173-S181. http://dx.doi.org/10.2337/dc19-S015

[4] Feng, X. T., Chen, Q., Xie, Z., et al. (2014). Pollen Typhae total flavone improves insulin resistance in high-fat diet and low-dose streptozotocin-induced type 2 diabetic rats. Bioscience biotechnology and biochemistry, 78, 1738-42. http://dx.doi.org/10.1080/09168451.2014.930318

[5] Garabadu, D., Krishnamurthy, S. (2017). Metformin attenuates hepatic insulin resistance in type-2 diabetic rats through PI3K/Akt/GLUT-4 signalling independent to bicuculline-sensitive GABAA receptor stimulation. Pharmaceutical biology, 55, 722-728. http://dx.doi.org/10.1080/13880209.2016.1268635

[6] Jiang, Y. D., Thakran, S., Bheemreddy, R., et al. (2015). Sodium salicylate reduced insulin resistance in the retina of a type 2 diabetic rat model. PloS One. 10, e0125505. http://dx.doi.org/10.1371/journal.pone.0125505

[7] Yue, X. Y., Luo, X. Y., Zhou, Z. J., et al. (2019). Selective electrochemical determination of tertiary butylhydroquinone in edible oils based on an in-situ assembly molecularly imprinted polymer sensor. Food Chemistry. 289, 84-94. http://dx.doi.org/10.1016/j.foodchem.2019.03.044

[8] Song, H. B., Xu, Y., Yang, X. W., et al. (2019). Tertiary butylhydroquinone alleviates gestational diabetes mellitus in C57BL/KsJ-Lep $\mathrm{db} /+$ mice by suppression of oxidative stress. Journal of Cellular Biochemistry. 120, 15310-15319. http://dx.doi.org/10.1002/jcb.28798

[9] Nishizono, S., Hayami, T., Ikeda, I., et, al. (2000). Protection against the diabetogenic effect of feeding tert-butylhydroquinone to rats prior to the administration of streptozotocin. Bioscience biotechnology and biochemistry. 64, 1153-1158. http://dx.doi.org/10.1271/bbb.64.1153

[10] Kang, K. W., Cho, M. K., Lee, C. H., et al. (2001). Activation of 
Phosphatidylinositol 3-Kinase and Akt by tertButylhydroquinone Is Responsible for Antioxidant Response Element-Mediated rGSTA2 Induction in H4IIE Cells. Molecular pharmacology. 59, 1147-1156. http://dx.doi.org/ 10.1124/mol.59.5.1147

[11] K Bahia, P., Pugh, V., Hoyland, K., et al. (2012). Neuroprotective effects of phenolic antioxidant tBHQ associate with inhibition of FoxO3a nuclear translocation and activity. Journal of neurochemistry, 123, 182-191. http://dx.doi.org/10.1111/j.1471-4159.2012.07877.x

[12] Li, S.T., Li, J.X., Shen, C., et al. (2014). tert-Butylhydroquinone (tBHQ) protects hepatocytes against lipotoxicity via inducing autophagy independently of Nrf2 activation. Biochimica et Biophysica Acta, 1841, 22-33. http://dx.doi.org/10.1016/j.bbalip.2013.09.004

[13] Foretz, M., Ancellin, N., Andreelli, F., et. al. (2005). Short-Term Overexpression of a Constitutively Active Form of AMP-Activated Protein Kinase in the Liver Leads to Mild Hypoglycemia and Fatty Liver. Diabetes, 54, 1331-1133. http://dx.doi.org/10.2337/diabetes.54.5.1331

[14] Malik, R. A., Zippel, N., Frömel, T., et. al. (2017). AMP-Activated Protein Kinase alpha2 in Neutrophils Regulates Vascular Repair via Hypoxia-Inducible Factor-1alpha and a Network of Proteins Affecting Metabolism and Apoptosis. $\begin{array}{llll}\text { Circulation } & \text { research, } & \text { 99-109. }\end{array}$ http://dx.doi.org/10.1161/CIRCRESAHA.116.309937

[15] Horikoshi, M., Hara, K., Ohashi, J., et al. (2006). A Polymorphism in the AMPK2 Subunit Gene Is Associated With Insulin Resistance and Type 2 Diabetes in the Japanese Population. Diabetes, 55, 919-923. http://dx.doi.org/10.2337/diabetes.55.04.06.db05-0727

[16] Zhao, L., Sun, L. N., Nie, H. B., et. al. (2014). Berberine improves kidney function in diabetic mice via AMPK activation. PLoS One. 9, e113398. http://dx.doi.org/10.1371/journal.pone.0113398

[17] Hwang, S.L., Jeyong, Y.T., Li, X., et. al. (2013). Inhibitory cross-talk between the AMPK and ERK pathways mediates endoplasmic reticulum stress-induced insulin resistance in skeletal muscle. British journal of clinical pharmacology, 169, 69-81. http://dx.doi.org/10.1111/bph.12124

[18] Shintyapina, A. B., Vavilin, V. A., Safronova, O. G., et. al. (2017). The gene expression profile of a drug metabolism system and signal transduction pathways in the liver of mice treated with tert-butylhydroquinone or 
3-(3'-tert-butyl-4'-hydroxyphenyl) propylthiosulfonate of sodium. PLoS One. 12, e0176939-e0176964. http://dx.doi.org/10.1371/journal.pone.0176939

[19] Lazaro, I, Lopez-Sanz, L, Bernal, S., et. al. (2018). Nrf2 Activation Provides Atheroprotection in Diabetic Mice Through Concerted Upregulation of Antioxidant, Anti-inflammatory, and Autophagy Mechanisms. Front Pharmacol. 9, 819-832. http://dx.doi.org/10.3389/fphar.2018.00819

[20] Liu, R., Wang, H. T., Xu, B. F., et. al. (2016). Cerebrovascular safety of sulfonylureas: the role of KATP channels in neuroprotection and the risk of stroke in patients with type 2 diabetes. Diabetes. 65, 2795-2809. http://dx.doi.org/10.2337/db15-1737

[21] Bunt, S. K., Mohr A. M., Bailey, J. M., et. al. (2012). Rosiglitazone and Gemcitabine in combination reduces immune suppression and modulates $\mathrm{T}$ cell populations in pancreatic cancer. Cancer immunology immunotherapy, 62, 225-236. http://dx.doi.org/ 10.1007/s00262-012-1324-3

[22] Zhao, Z., Sun, X. L., Guo, X. D., et. al. (2017). Rosiglitazone Exerts an Anti-depressive Effect in Unpredictable Chronic Mild-Stress-Induced Depressive Mice by Maintaining Essential Neuron Autophagy and Inhibiting Excessive Astrocytic Apoptosis. Frontiers in molecular neuroscience. 10, 293-309. http://dx.doi.org/10.3389/fnmol.2017.00293

[23] Zhang, W. X., Tai, G. J., Li, X. X., et. al. (2019). Inhibition of neointima hyperplasia by the combined therapy of linagliptin and metformin via AMPK/Nox4 signaling in diabetic rats. Free radical biology and medicine. 143, 153-163. http://dx.doi.org/10.1016/j.freeradbiomed.2019.07.030

[24] Bin-Jumah, M. N. (2019). Antidiabetic Effect of Monolluma quadrangula Is Mediated via Modulation of Glucose Metabolizing Enzymes, Antioxidant Defenses, and Adiponectin in Type 2 Diabetic Rats. Oxidative medicine and cellular longevity, 2019, 6290143. http://dx.doi.org/10.1155/2019/6290143

[25] Lei, Y. Y., Gong, L. L., Tan, F. G., et. al. (2019). Vaccarin ameliorates insulin resistance and steatosis by activating the AMPK signaling pathway. European journal of pharmacology, 851, 13-24. http://dx.doi.org/10.1016/j.ejphar.2019.02.029

[26] Liu, H. S., Qi, X. Y., Yu, K. K., et. al. (2019). AMPK activation is involved in hypoglycemic and hypolipidemic activities of mogroside-rich extract from Siraitia grosvenorii (Swingle) fruits on high-fat diet/streptozotocin-induced diabetic mice. Food \& Function, 10, 151-162. http://dx.doi.org/10.1039/c8fo01486h 
[27] Zhu, T. T., Zhang, W. F., Yin, Y. L., et al. (2019). MicroRNA-140-5p targeting tumor necrosis factor-alpha prevents pulmonary arterial hypertension. Journal of cellular physiology, 234, 9535-9550. http://dx.doi.org/10.1002/jcp.27642

[28] Wu, W., Piao, H., Wu, F. S., et. al. (2019). Yu Jin Pulvis inhibits carbon tetrachloride-induced liver fibrosis by blocking the MAPK and PI3K/Akt signaling pathways. American journal of translational research, 11, 5998-6006.

[29] Dai, J. H., Sun, Y., Chen, D. Y., et. al. (2019). Negative regulation of $\mathrm{PI} 3 \mathrm{~K} / \mathrm{AKT} / \mathrm{mTOR}$ axis regulates fibroblast proliferation, apoptosis and autophagy play a vital role in triptolide-induced epidural fibrosis reduction. European journal of pharmacology, 864, 172724-172734. http://dx.doi.org/10.1016/j.ejphar.2019.172724

[30] Rai, U., Kosuru, R., Prakash, S., et. al. (2019). Tetramethylpyrazine prevents diabetes by activating PI3K/Akt/GLUT-4 signalling in animal model of type-2 diabetes. Life $\quad$ sciences, $236, \quad 116836-116870$. http://dx.doi.org/10.1016/j.lfs.2019.116836

[31] Dayoub, R., Vogel, A., Schuett, J., et. al. (2013). Nrf2 activates augmenter of liver regeneration (ALR) via antioxidant response element and links oxidative stress to liver regeneration. Molecular medicine, 19, 237-244. http://dx.doi.org/10.2119/molmed.2013.00027

[32] Hu, L., Tian, K., Zhang, T., et. al. (2019). Cyanate Induces Oxidative Stress Injury and Abnormal Lipid Metabolism in Liver through Nrf2/HO-1. Molecules, 24, 3231-3250. http://dx.doi.org/10.3390/molecules24183231

[33] Aghanoori, M. R., Smith, D. R., Shariati-Ievari, S., et. al. (2019). Insulin-like growth factor-1 activates AMPK to augment mitochondrial function and correct neuronal metabolism in sensory neurons in type 1 diabetes. Molecular metabolism, 20, 149-165. http://dx.doi.org/10.1016/j.molmet.2018.11.008

[34] Rachubik, P., Szrejder, M., Rogacka, D., et. al. (2018). The TRPC6-AMPK Pathway is Involved in Insulin-Dependent Cytoskeleton Reorganization and Glucose Uptake in Cultured Rat Podocytes. Cellular physiology and biochemistry, 51, 393-410. http://dx.doi.org/10.1159/000495236

[35] Long, Y. C., Zierath, J. R. (2006). AMP-activated protein kinase signaling in metabolic regulation. Journal of clinical investigation, 116, 1776-1783. http://dx.doi.org/ 10.1172/JCI29044

[36] Zhang, W. C., Zou, M. H., Wang, Q. L., et. al. (2013). Liver Kinase B1 Is Required for White Adipose Tissue Growth and Differentiation. Diabetes, 62, 
2347-2358. http://dx.doi.org/ 10.2337/db12-1229

[37] Okon, S. I., Coughlan, A. K., Zhang, C., et. al. (2014). Protein kinase LKB1 promotes RAB7-mediated neuropilin-1 degradation to inhibit angiogenesis. Journal of clinical investigation, 124, 4590-4602. http://dx.doi.org/10.1172/JCI75371

[38] Sun, Y. K., Zhou, S. S., Guo, H., et. al. (2019). Protective effects of sulforaphane on type 2 diabetes-induced cardiomyopathy via AMPK-mediated activation of lipid metabolic pathways and NRF2 function. Metabolism. 102, 1-28. http://dx.doi.org/10.1016/j.metabol.2019.154002

[39] Han, Y. M., Hu, Z. M., Cui, A. Y., et. al. (2019). Post-translational regulation of lipogenesis via AMPK-dependent phosphorylation of insulin-induced gene. Nature communications, 10, 623-636. http://dx.doi.org/10.1038/s41467-019-08585-4

[40] Nissen, S. E., Wolski, K. (2007). Effect of rosiglitazone on the risk of myocardial infarction and death from cardiovascular causes. The New England journal of medicine, 356, 2457-2471. http://dx.doi.org/10.1056/NEJMoa072761 


\section{Figure legends}

Figure 1. Effects of Tert-butylhydroquinone (TBHQ) treatment on body weight, fasting blood glucose (FBG), postprandial blood glucose (PBG), and oral glucose tolerance test (OGTT) in type 2 diabetes mellitus (T2DM) mice. A. the protocol of the animal experiment; B. FBG; C. PBG; D. body weight; E. OGTT. ${ }^{* *} P<0.01$ vs. Control, ${ }^{\#} P<0.01$ vs. T2DM. Data are represented as mean $\pm \mathrm{SD}(\mathrm{n}=10)$.

Figure 2. Effects of TBHQ on liver steatosis of diabetic mice and on HepG2 cells survival. A. HE staining of the liver tissue, glycogen was staining as red and nucleus was staining as blue $(\times 200)$. B. Hoechst staining of HepG2 cells $(\times 200)$, the red arrow indicated the apoptotic cell.

Figure 3. The expression of the related protein level of glucose metabolism in the liver of the mice and the HepG2 cells. A-B. the expression of GLUT4 in the liver of the mice and the HepG2 cells; C-D. the expression of GSK3 $\beta$ in the liver of the mice and the HepG2 cells; E-F. the phosphorylation level of PI3K in the liver of the mice and the HepG2 cells; G-H. the phosphorylation level of AKT in the liver of the mice and the HepG2 cells. ${ }^{*} P<0.05$ vs. Control, ${ }^{\$} P<0.05$ vs. T2DM, ${ }^{\&} P<0.05$ vs. $\mathrm{HClO}+$ insulin. Results are represented as mean $\pm \mathrm{SD}(\mathrm{n}=3)$.

Figure 4. Effect of TBHQ on the expression of AMPKa2. A. the expression of AMPK $\alpha 2$ in the liver of the mice; B. the expression of AMPK $\alpha 2$ in HepG2 cells. ${ }^{*} P<0.05$ vs. Control, ${ }^{\#} P<0.05$ vs. T2DM, ${ }^{\&} P<0.05$ vs. HClO+insulin. Results are represented as mean $\pm \mathrm{SD}(\mathrm{n}=3)$.

Figure 5. TBHQ could alleviate insulin resistance of HepG2 cells via AMPK $\alpha 2 / P I 3 K / A K T$ pathway. A. the expression of GLUT4 in HepG2 cells; B. the expression of GSK3 $\beta$ in HepG2 cells; C. the phosphorylation level of PI3K in HepG2 cells; D. the phosphorylation level of AKT in HepG2 cells. ${ }^{*} P<0.05$ vs. Control, ${ }^{\&} P<0.05$ vs. HClO+insulin, ${ }^{\#} P<0.05$ vs. siPRKAA2+Control, ${ }^{\$} P<0.05$ vs. siPRKAA2+HClO+insulin, ${ }^{\wedge} P<0.05$ vs. siPRKAA2+HClO+TBHQ+insulin. Results are represented as mean $\pm S D(n=3)$.

Figure 6. Schematic diagram showing that TBHQ alleviates T2DM via AMPK $\alpha 2 / A K T / P I 3 K$ pathway. During T2DM, TBHQ activates AMPKa2, then 
AMPK $\alpha 2$ promotes phosphorylation of phosphatidylinositol 3-kinase subunit p85 and AKT. p-AKT reacts with glucose transporter GLUT4 and glycogen synthesis kinase GSK3 $\beta$ in liver tissue, and eventually alleviating T2DM. 


\section{Figure 1}

A

High-sucrose-high-fat diet

\section{Sacrificed}



B

C

$\begin{array}{ll}\bullet \text { Control } & \text { T2DM } \\ - \text { Control+TBHQ } & \rightarrow \mathrm{T} 2 \mathrm{DM}+\mathrm{TBHQ}+\text { rosiglitazone }\end{array}$

- Control
- Control+TBHQ $¥ \mathrm{~T} 2 \mathrm{DM}$
$\mp \mathrm{T} 2 \mathrm{DM}+\mathrm{TBHQ}$
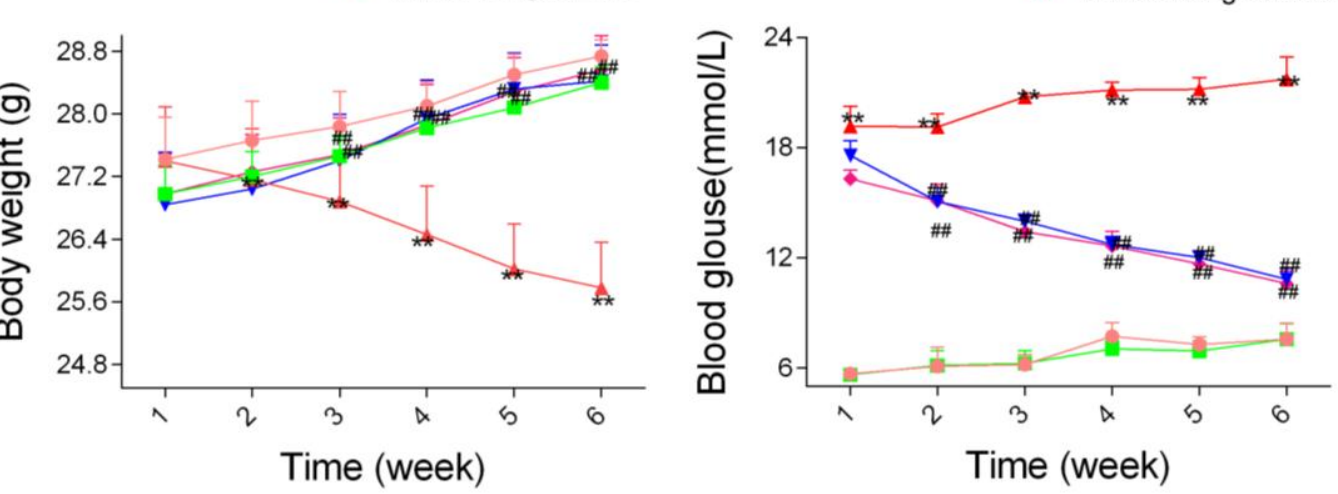

D

E

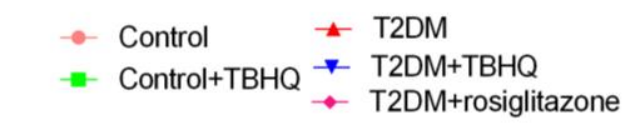
- Control $\quad$ - T2DM
- Control+TBHQ $\rightarrow \mathrm{T} 2 \mathrm{DM}+\mathrm{TBHQ}$

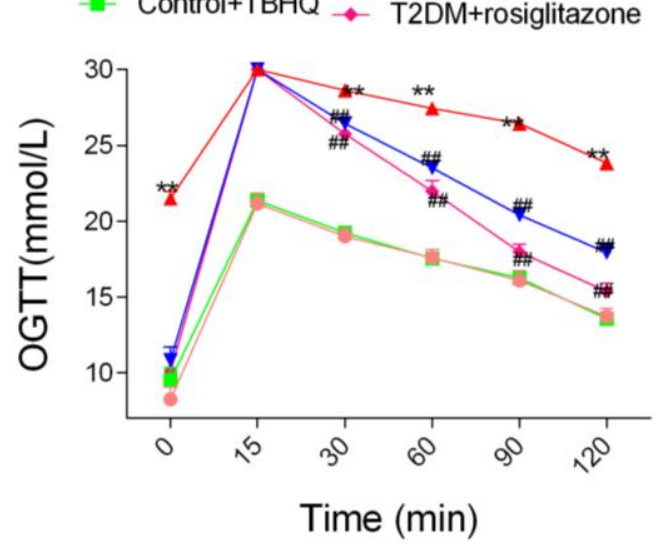


Figure 2
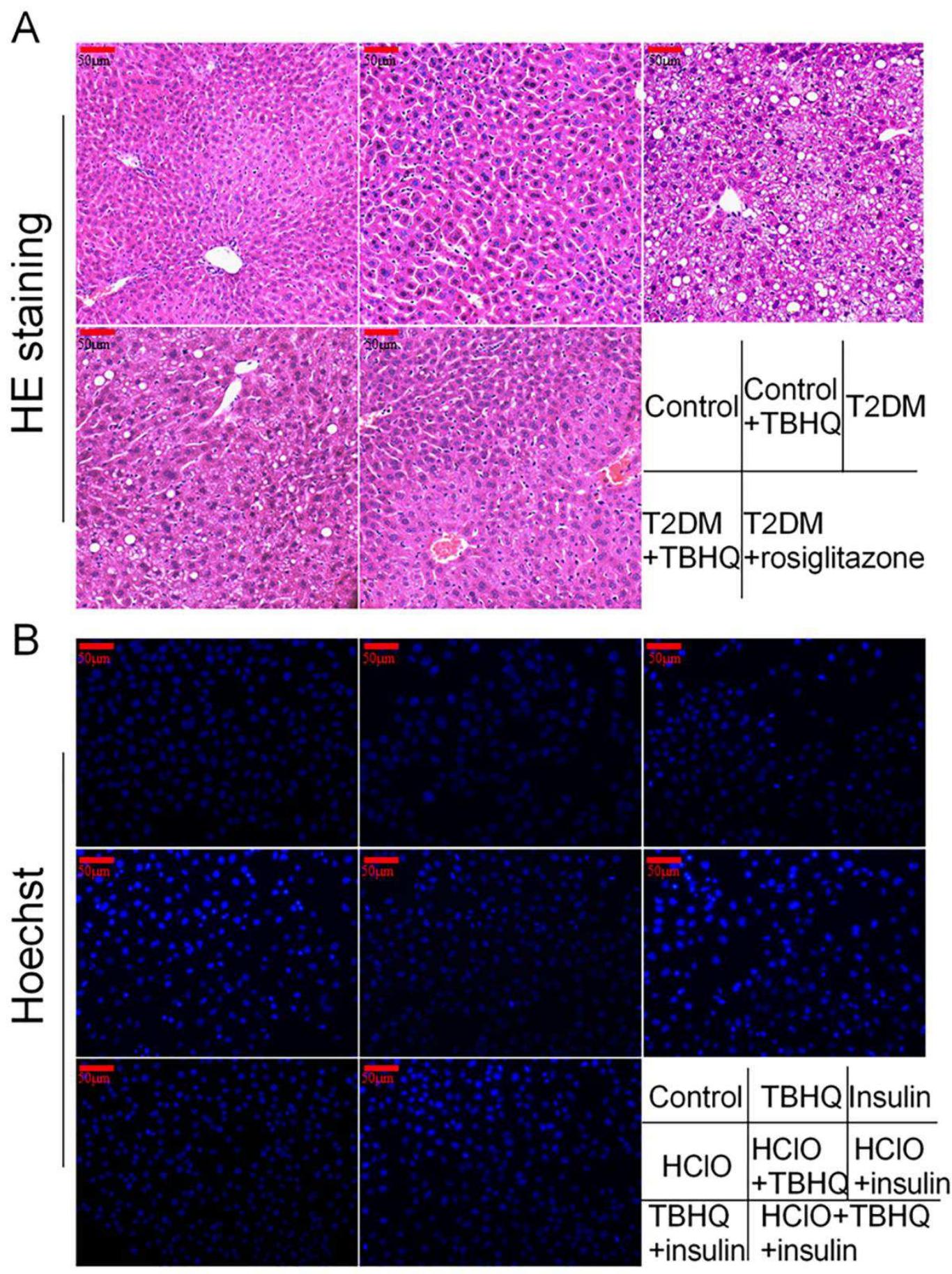
Figure 3
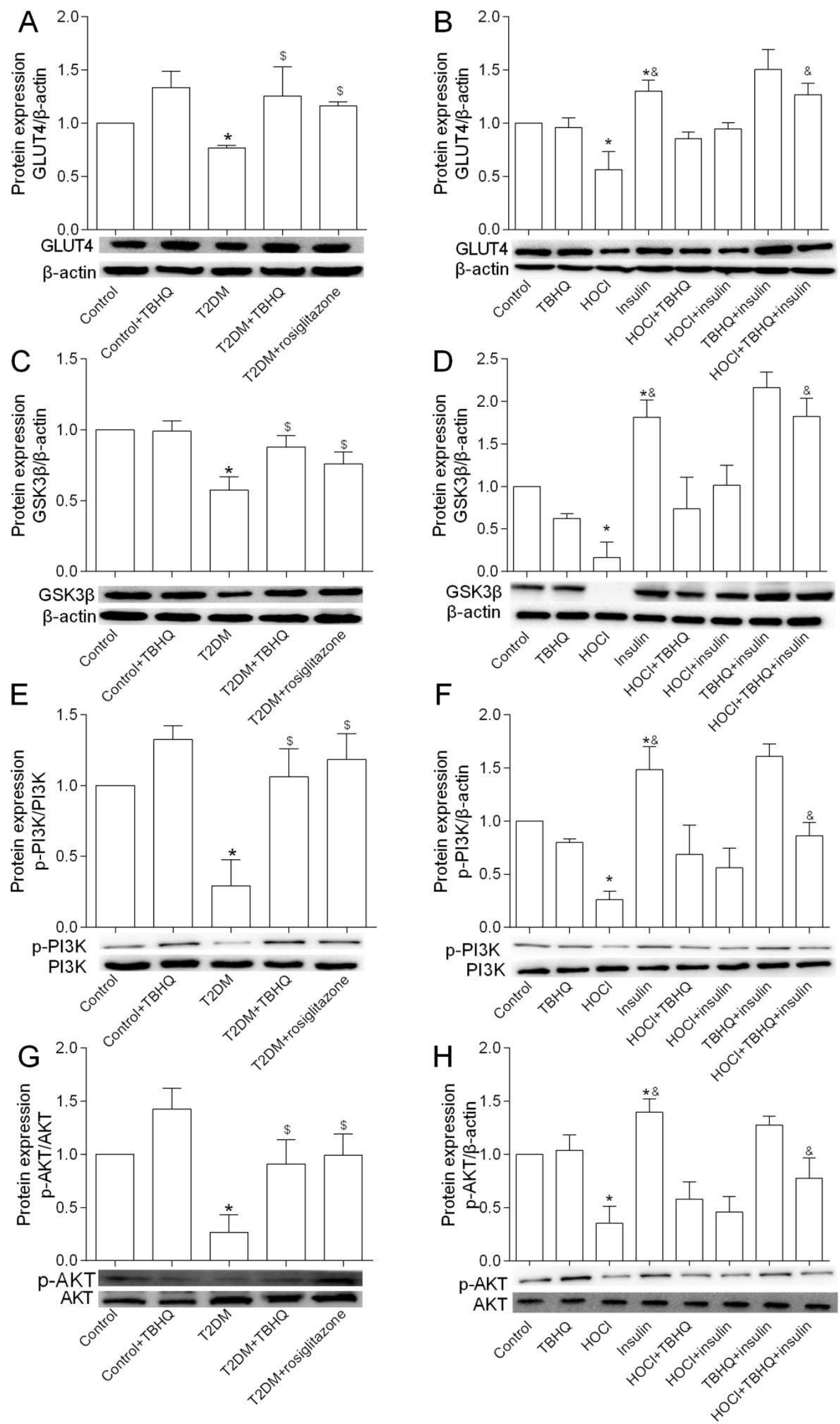
Figure 4

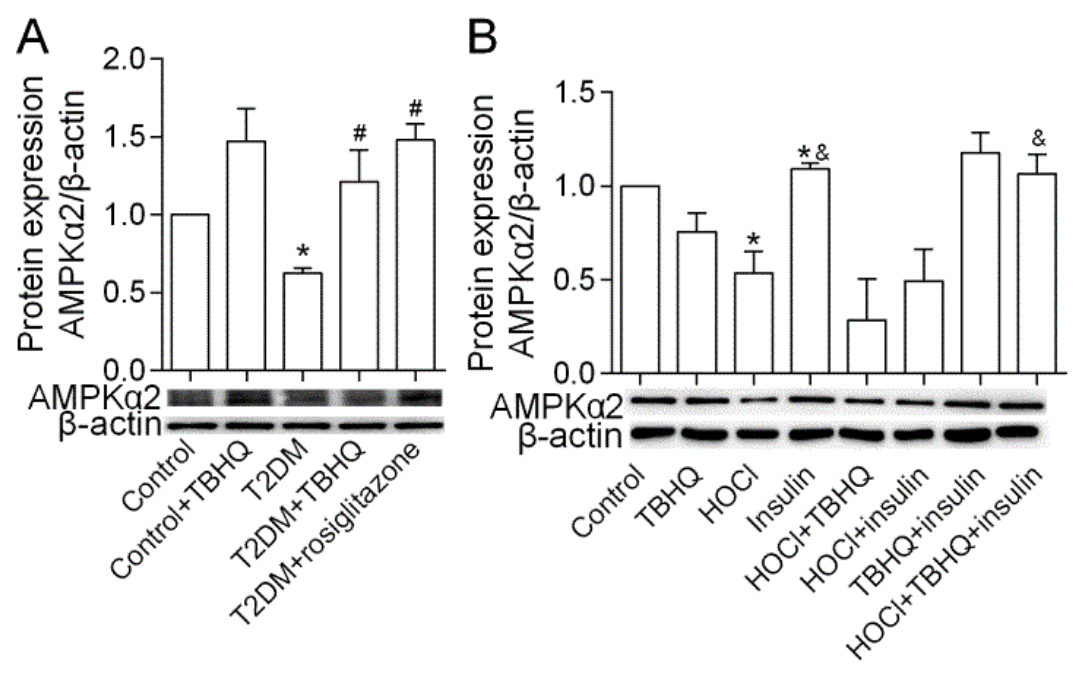

Figure 5

A

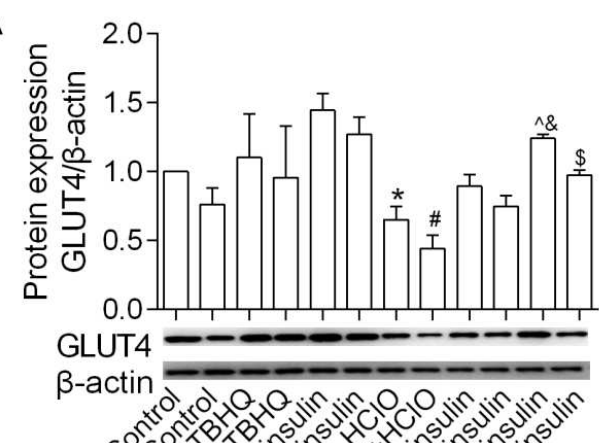

C

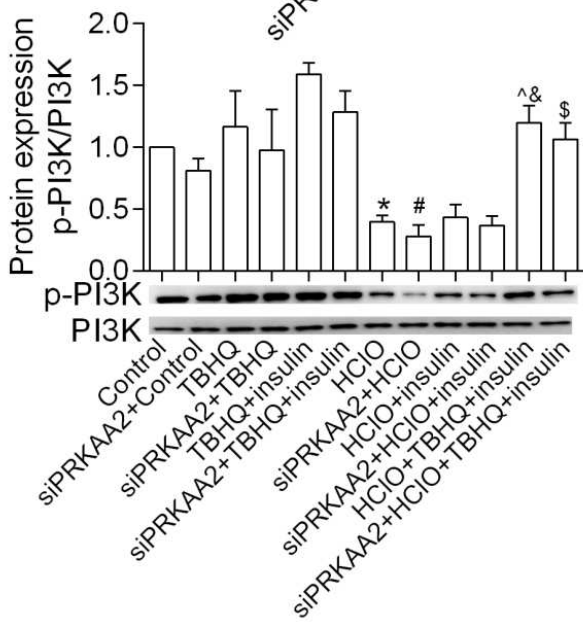

B

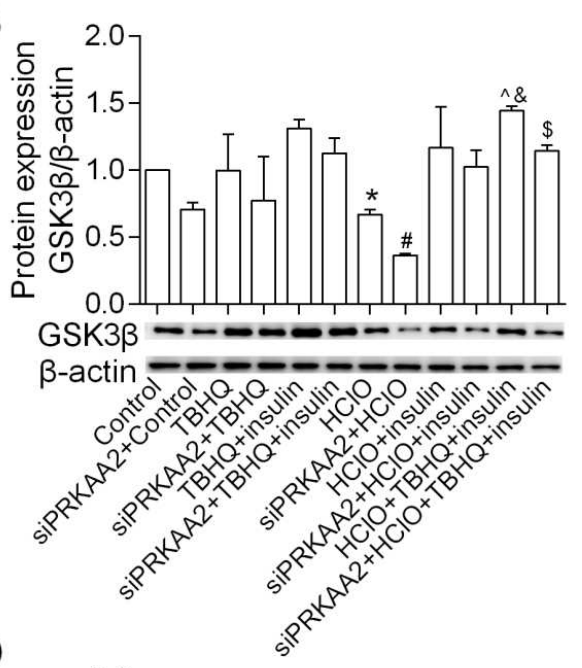

듬

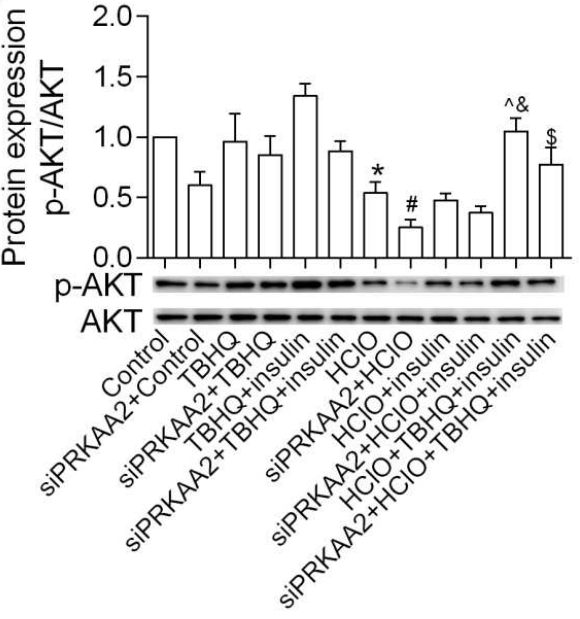


Figure 6

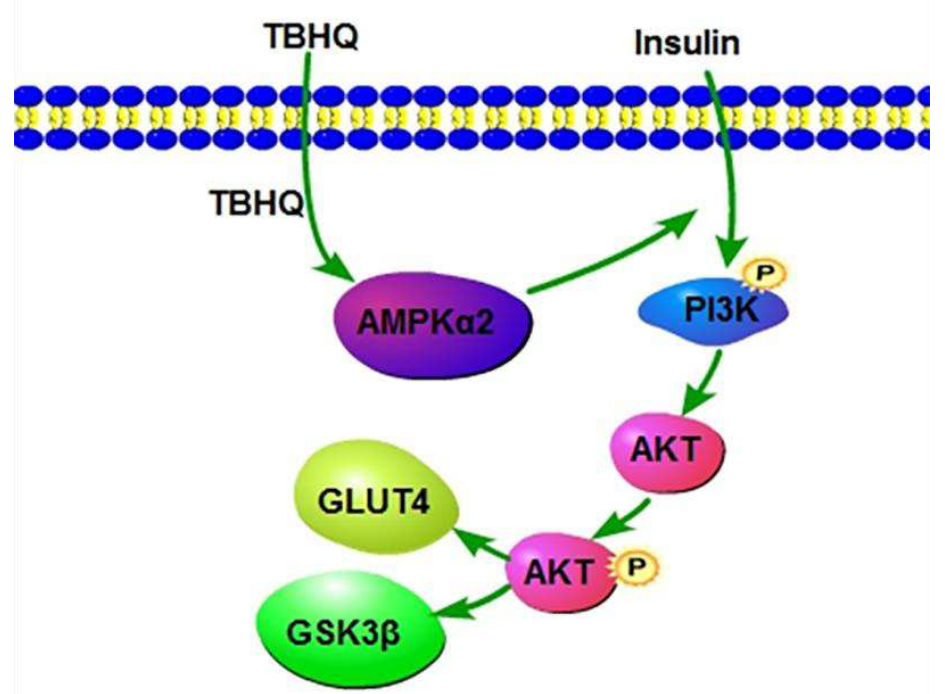




\section{Figures}

A

High-sucrose-high-fat diet

B
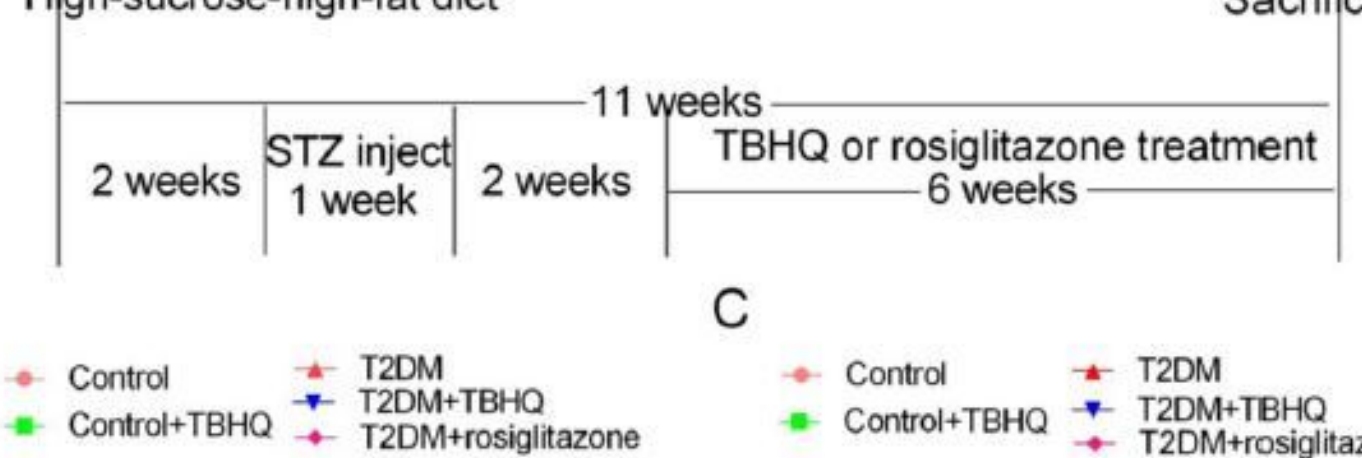

C
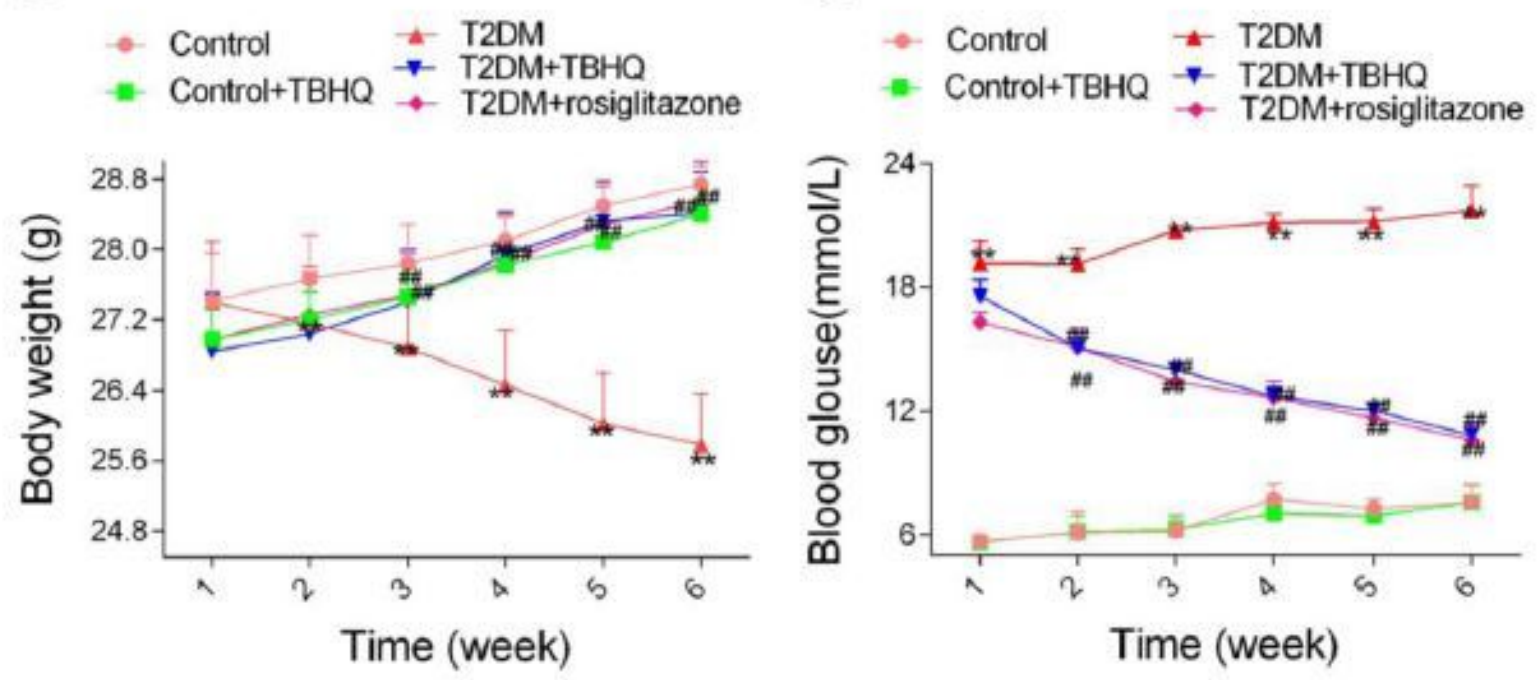

D

$E$


Figure 1

Effects of Tert-butylhydroquinone (TBHQ) treatment on body weight, fasting blood glucose (FBG), postprandial blood glucose (PBG), and oral glucose tolerance test (OGTT) in type 2 diabetes mellitus 
(T2DM) mice. A. the protocol of the animal experiment; B. FBG; C. PBG; D. body weight; E. OGTT. ${ }^{* * P<0.01}$ vs. Control, \#\#P<0.01 vs. T2DM. Data are represented as mean \pm SD $(n=10)$.
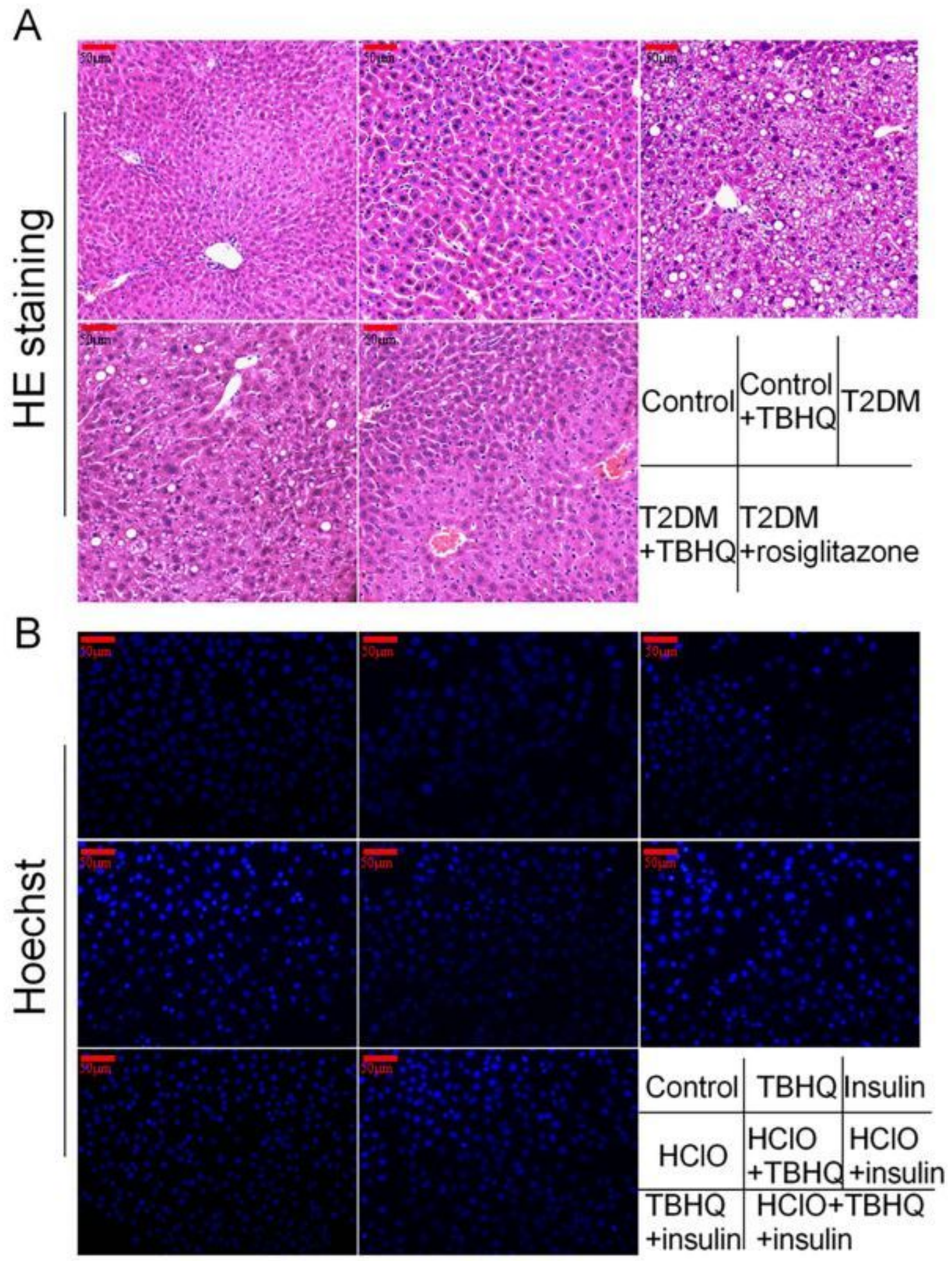

Figure 2

Effects of TBHQ on liver steatosis of diabetic mice and on HepG2 cells survival. A. HE staining of the liver tissue, glycogen was staining as red and nucleus was staining as blue $(\times 200)$. B. Hoechst staining of HepG2 cells $(\times 200)$, the red arrow indicated the apoptotic cell. 

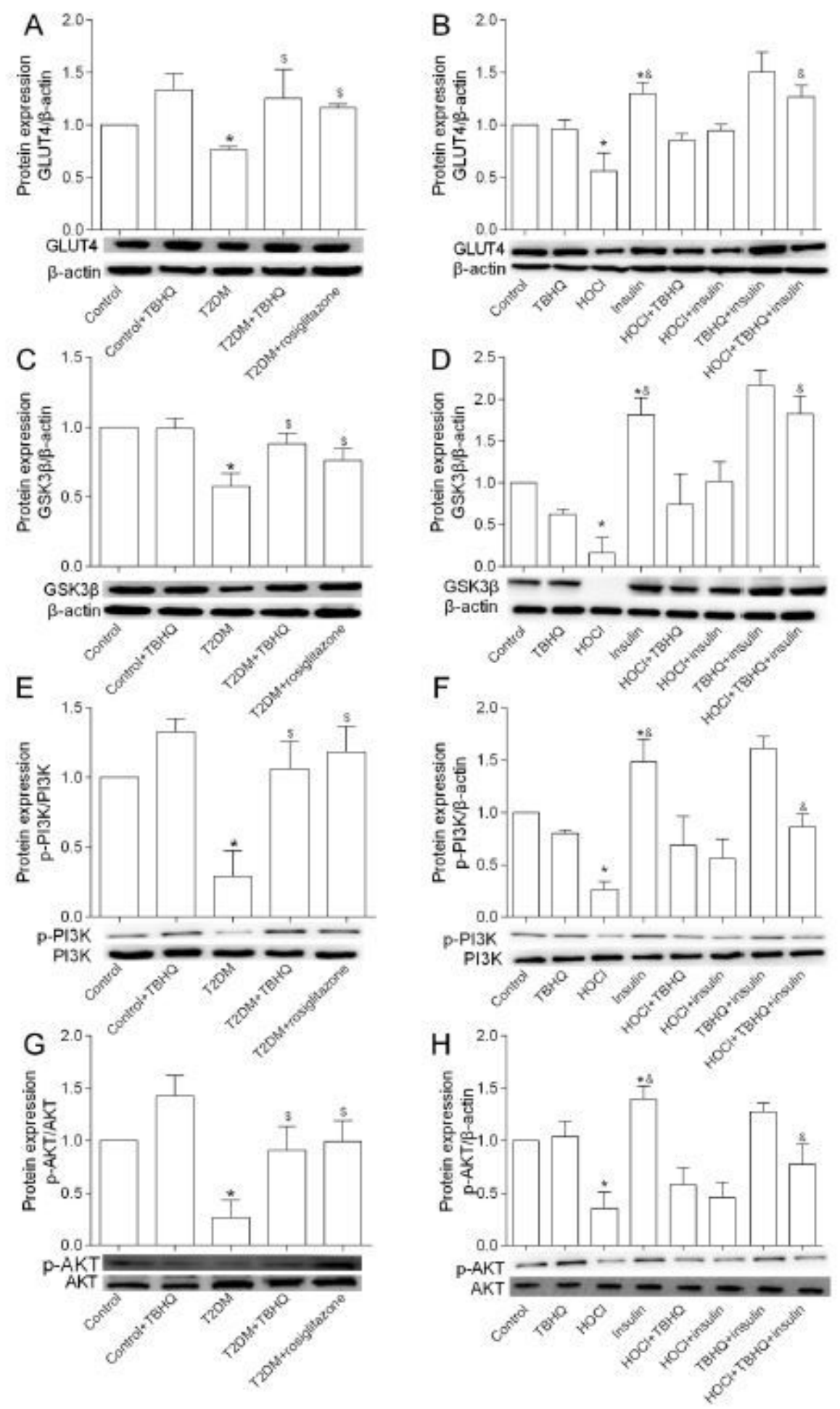

\section{Figure 3}

The expression of the related protein level of glucose metabolism in the liver of the mice and the HepG2 cells. A-B. the expression of GLUT4 in the liver of the mice and the HepG2 cells; C-D. the expression of GSK3 $\beta$ in the liver of the mice and the HepG2 cells; E-F. the phosphorylation level of PI3K in the liver of the mice and the HepG2 cells; G-H. the phosphorylation level of AKT in the liver of the mice and the HepG2 
cells. ${ }^{*}<0.05$ vs. Control, $\$ \mathrm{P}<0.05$ vs. $\mathrm{T} 2 \mathrm{DM}, \& \mathrm{P}<0.05$ vs. $\mathrm{HClO}+$ insulin. Results are represented as mean $\pm \operatorname{SD}(n=3)$.

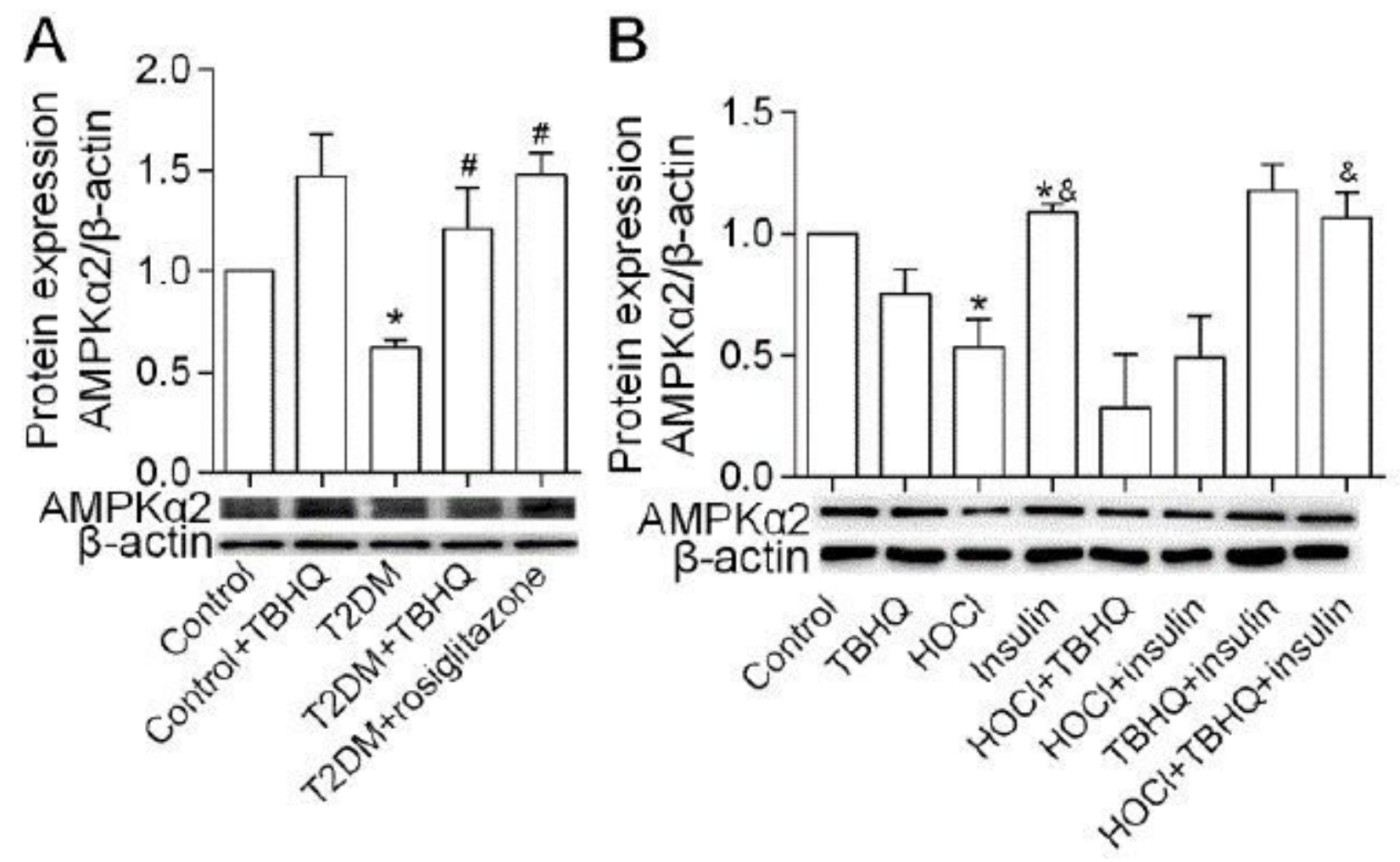

Figure 4

Effect of TBHQ on the expression of AMPKa2. A. the expression of AMPKa2 in the liver of the mice; B. the expression of $A M P K a 2$ in HepG2 cells. ${ }^{*} P<0.05$ vs. Control, $\# P<0.05$ vs. T2DM, \&P<0.05 vs. HClO+insulin. Results are represented as mean \pm SD $(n=3)$. 

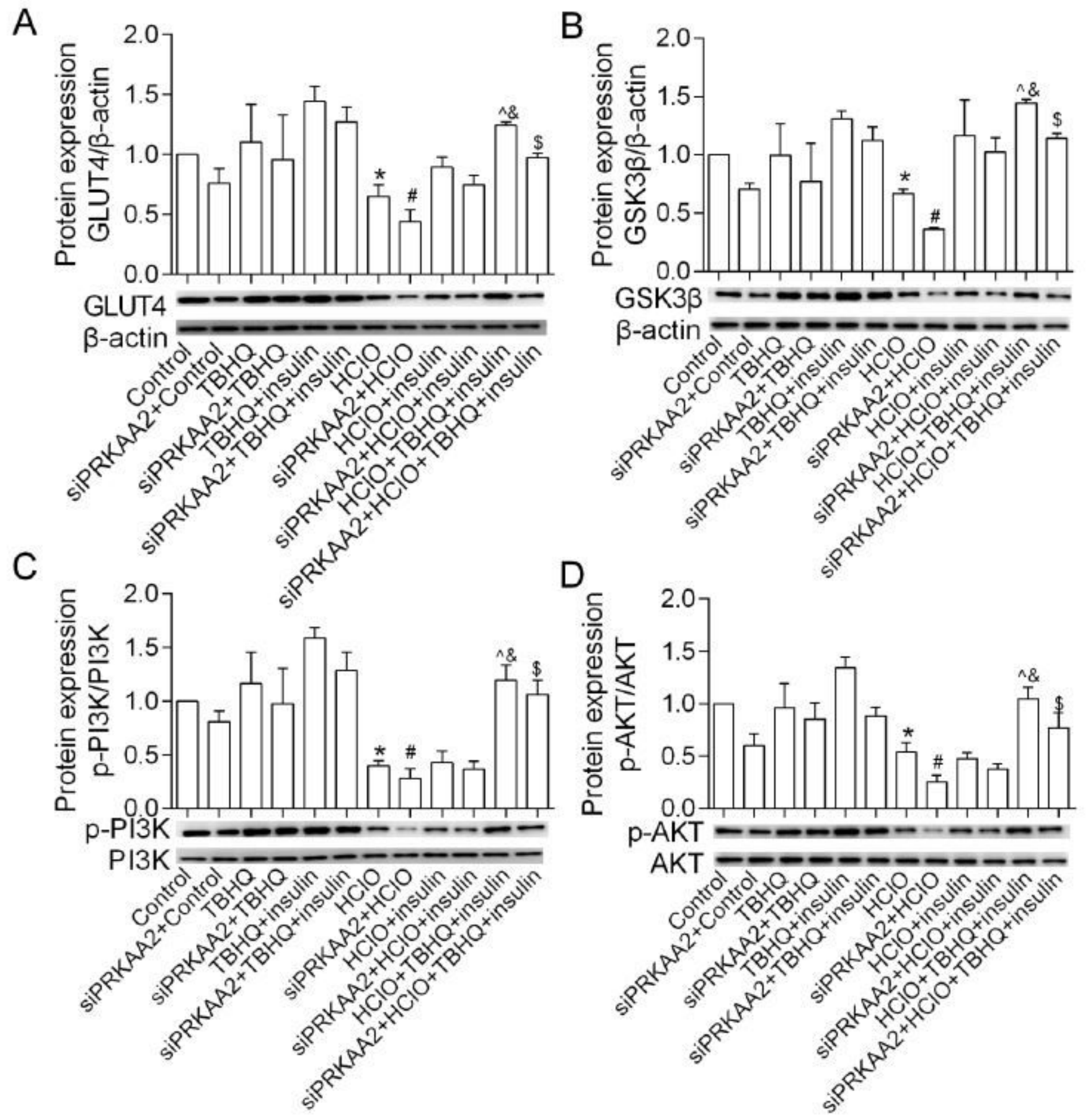

Figure 5

TBHQ could alleviate insulin resistance of HepG2 cells via AMPKa2/PI3K/AKT pathway. A. the expression of GLUT4 in HepG2 cells; B. the expression of GSK3 $\beta$ in HepG2 cells; C. the phosphorylation level of PI3K in HepG2 cells; D. the phosphorylation level of AKT in HepG2 cells. ${ }^{*} P<0.05$ vs. Control, $\& P<0.05$ vs. $\mathrm{HClO}+$ insulin, $\# \mathrm{P}<0.05$ vs. siPRKAA2+Control, $\$ \mathrm{P}<0.05$ vs. siPRKAA2+HClO+insulin, ${ }^{\wedge} \mathrm{P}<0.05$ vs. siPRKAA2+HClO+TBHQ+insulin. Results are represented as mean $\pm \mathrm{SD}(\mathrm{n}=3)$. 




Figure 6

Schematic diagram showing that TBHQ alleviates T2DM via AMPKa2/AKT/PI3K pathway. During T2DM, TBHQ activates AMPKa2, then AMPKa2 promotes phosphorylation of phosphatidylinositol 3-kinase subunit p85 and AKT. p-AKT reacts with glucose transporter GLUT4 and glycogen synthesis kinase GSK3 $\beta$ in liver tissue, and eventually alleviating T2DM.

\section{Supplementary Files}

This is a list of supplementary files associated with this preprint. Click to download.

- Supplementaryfigure.pdf 